\title{
EN TORNO A ALGUNOS MSS. DE APOLONIO DE RODAS CONSERVADOS EN BIBLIOTECAS ESPANOLAS: NOTAS DE PALEOGRAFIA
}

\begin{abstract}
Taking as a basis for his study the Escorialensis $\Sigma$ III 3 (102) which was written by A. Apostolis, A. Damilas and G. Gregoropulos, the author studies other mss. of Apollonius in Spanish libraries and identifies new copies by Z. Callierges ( $\Sigma$ III 20 [119], $\Phi$ I 4 [182], $\Omega$ IV 7 [559] partially and $\Phi$ III 14 [233]), who was not the copyist of Matritensis BN 4564 (N 25) as has been maintained since Vogel-Gardthausen. Besides that, the author identifies the hand of P. Hypsilas (R I 16 [16] and Matritensis BN 4714 [O 49]), that of John of Corone (Matritensis BN 4549 [N 10]) and other copies made by A. Apostolis ( $\Sigma$ III 15 [114] and $\Phi$ II 19 [206] partially).

Other mss. with their problems and peculiarities are mentioned and studied.
\end{abstract}

En la excelente descripción que D. Harlfinger ha dado del Escorialensis T II 13 (152) ', ms. copiado por Antonio Damilás ${ }^{2}$ y que pertene-

\footnotetext{
1 P. Moraux - D. Harlfinger-D. Reinsch-J. Wiesner, Aristoteles Graecus. Die griechischen Manuskripte des Aristotcles I. Alexandrien - London, Berlín - Nueva York 1976, pp. 161-162.

2 Hermano de Demetrio Damilás, el editor del primer libro griego impreso en Milán en 1476 (véase A. J. Geanakoplos, Byzantium and the Renaissance. Greek Scholars in Venice. Studies in the Dissemination of Greek Learning from Byzantium to Western Europe, Hamden, Connecticut, 1973, p. 224), este copista ejerció su actividad entre los años 1480 y 1491 en Italia y Creta. Véase M. Vogel - V. Gardthausen, Die griechischen Schreiber des Mittelalters und der Renaissance, Leipzig

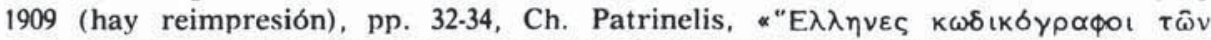

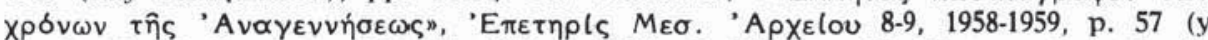
reseña de P. Speck en $B Z$ 55, 1962, p. 322), J. Wiesner-U. Victor, «Griechische Schreiber der Renaissance. Nachträge zu den Repertorien von Vogel-Gardthausen, Patrinelis, Canart, De Meyier», RSBN 8, 1971, p. 55 y D. Harlfinger, Die Text-

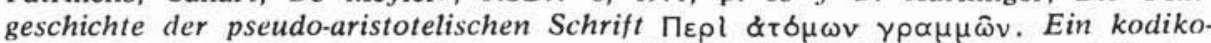
logisch-kulturgeschichtlicher Beitrag zur Klärung der Ueberlieferungsverhältnisse in Corpus Aristotelicum, Amsterdam 1971, p. 411 y muestras cle su escritura en H. Omont, Fac-similés de manuscrits grecs des XVe et XVIe siècles, París 1887 (hay reimpresión), lám. 3, M. Wittek, Album de paléographie grecque. Spécimens d'écritures livresques du IIIe siècle avant J. C. au XVIIIe siècle, conservés dans des
} 
ció a Mateo Dándolo ${ }^{3}$, señala este investigador que otro $\mathrm{ms}$. de la Real Biblioteca signado por este mismo copista y copiado en su mayor parte por él, el $\Sigma$ III 3 (102), contiene en los ff. 10-29 la mano de Aristóbulo Apostolidis ${ }^{4}$, conocido más tarde como Arsenio de Monenvasia e hijo

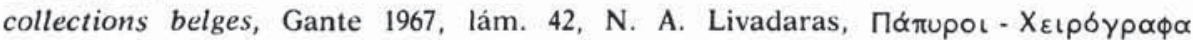

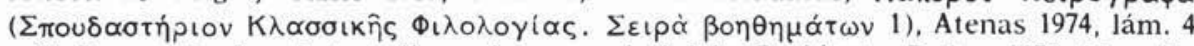
y S. Bernardinello, Atutografi greci e greco-latini in Occidente, Paclua 1979, lím. 45: según G. de Andrés, Catálogo de los códices griegos de la Real Biblioteca de El Escorial, III, Madrid 1967, p. 341, en el Real Monasterio hay un solo ms. más de Antonio Damilás, aparte de los otros que identifica Harlfinger y que fueron de Mateo Dándolo (véase sobre su colección A. Revilla, Catálogo de los códices gricgos de la Biblioteca de El Escorial, I, Madrid 1936, pp. LXVIII-LXXVI); se trata del Ф II 9 (206) que perteneció a Don Diego Hurtado de Mendoza y fue escrito en 1489 (véase f. 342) por este amanuense en Creta (véase De Andrés, Catálogo de los códices griegos de la Real Biblioteca de El Escorial, II, Madrid 1965, pp. 35-36). Por lo que se refiere a Demetrio, la bibliografía fundamental está recogida on E. Gamillscheg-D. Harlfinger, "Specimen eines Repertoriums der griechischen Kopisten", JOB 27, 1978, p. 304 y Harlfinger, Specimina griechischer Kopisten der Renaissance, I: Griechen des 15. Jahrhunderts, Berlín 1974, pp. 33-34 (láminas en Harlfinger, Die Textgeschichte, lám. 7, Idem, Specimina, lám. 75 y P. Krafft, Die handschriftliche Ueberlieferung von Cornutus' Theologia Graeca, Heidelberg 1975 , lám. VIII). Es de notar que la lám. 7 de Harlfinger, Die Textgeschichte, aparece atribuida al librarius Florentinus (véase o. c., p. 417), señalando este investigador que el Matritensis BN 4578 (N 41), ff. 54-63v es del mismo copista; no obstante, en las publicaciones posteriores la identificación queda ya aclarada y véasc ahora, además, P. Canart, "Un copiste expansif: Jean Sévère de Lacédémonie" en K. Treu (ed.), Studia Codicologica, I, Berlín 1977, p. 123, n. 2, así como los otros trabajos de este mismo autor, "Nouvelles recherches et nouveaux instruments de travail dans le domaine de la codicologie", Scrittura e civiltà 3, 1979, p. 278, "Démétrius Damilas, alias le librarius Florentinus", RSBN 14-16, 1977-1979, pp. 281-347 y "De la catalographie à l'histoire du livre. Vingt ans de recherches sur les manuscrits grecs», Byzantion 50, 1980, pp. 598-599.

3 Se pueden reconocer más de cuarenta códices provenientes de la colección de este personaje en la Biblioteca del Real Monasterio; véase lo dicho en la nota anterior.

4 Véase, en general, Vogel-Gardthausen, o. c., pp. 42-44, Patrinelis, o. c., pp. 68 69, P. Canart, "Scribes grecs de la Renaissance. Addlitions et corrections aux répertoires de Vogel-Gardthausen et de Patrinélis», Scriptorium 17, 1963, pp. 59 y 67, B. L. Fonkič, "Grečeskie piscy epochi vozroždenija», $V V$ 26, 1965, p. 269, Wiesner Victor, o. c., p. 52, Harlfinger, Die Textgeschichte, p. 408, Geanakoplos, o. c., pp. 167-200 y, en especial, M. Wittek, "Pour une étude du scriptorium de Michel Apostolès et consorts», Scriptorium 7, 1953, pp. 290-297, así como P. Canart, "Note sur l'écriture de Michel et Aristobule Apostolès et sur quelques manuscrits attribuables à ce dernier» en A. L. di Lello Finuoli, Un esemplare autografo di Arsenio e il «Florilegio» di Stobeo, Roma 1961, pp. 87-101 (con tres cuadros de peculiaridades paleográficas y 18 láminas); otras muestras de su escritura en Omont, o. c. lám. 5 (para este autor Arsenio de Monenvasia y Aristóbulo Apostolidis son dos personas diferentes, hermanos, y del primero da otra lámina, la n. ${ }^{\circ} 6$ ), Wittek, Album, láms. 43 y 46, E. Follieri, Codices Bibliothecae Vaticanae selecti temporum locorumque ordine digesti commentariis et transcriptionibus instructi, Ciudad del Vaticano 1969, lám. 66, R. Merkelbach - H. Van Thiel, Griechisches Leseheft, Gotinga 1965, lám. 8, A. Biedl, «Eine griechische Handschrift aus der Sammlung des Bohuslaw v. Lobkowicz», Mitteilungen des Vereins für Geschichte der Deutschen in 
de Miguel Apostolio. La identificación de este último copista ${ }^{5}$ resulta de interés ya que, por un lado, según G. de Andrés ${ }^{6}$, el único ms. escorialense debido a su pluma era el X IV 20 (415) que fue de Antonio Agustín ${ }^{7}$; de otra parte, el contenido del $\Sigma$ III 3, que tiene bastante importancia, en virtud de la presencia en él del texto de Apolonio Rodio apuntaba ya - por las razones que más adelante examinaremos- hacia una colaboración del hijo de Miguel Apostolio. Es precisamente siguiendo esta dirección como trataremos de identificar la tercera mano de este códice (ff. 2-9v y otras de diversos mss. de El Escorial o la Biblioteca Nacional de Madrid que contienen las mismas obras o bien otras diferentes relacionadas de algún modo.

En opinión de F. Vian ${ }^{8}$, la tercera familia de los mss. de Apolonio de Rodas no es sino una subfamilia de la primera que está formada, básicamente, por el famoso Laurentianus XXXII, 9 de Sófocles, Esquilo y Apolonio copiado entre los años 960 y 980 y enviado por Juan Aurispa 9 desde Constantinopla, en el año 1423, a Florencia donde todavía se encuentra. El prototipo de esta tercera familia, el llamado protocretensis, debió ser un códice originario igualmente de Constantinopla y pasar a Creta donde, en 1480, fue copiado por Antonio Damilás quien omitió los escolios que, junto a otras obras ${ }^{10}$, se conservaban en su modelo;

Bühmen, 71, 1933, lám. frente a p. 94 y N. Wilson, Mediaeval Greek Bookhands. Examples selected from Greek Manuscripts in Oxford Libraries, Cambridge, Mass., 1972-1973, lám. 83. Por lo que se refiere al padre, Miguel Apostolio, bibliografía abundante en el tratamiento de su vida y obra presenta Geanakoplos, o. c., pp. 73 110; su letra es bien conocida y está presente en casi todos los álbunes citados.

5 Se debe a Harltinger, Aristoteles Graecus, p. 162, ya que ni Revilla ni otros autores, que sepamos, han parado mientes en ello; el $\Sigma$ III 3 (véase Revilla, o. c., pp. 343-346) fue también de M. Dándolo.

6 Catálogo, III, p. 342.

7 De Andrés, Catálogo, 11, pp. 352-353; la identificación parece correcta.

8 Exposición pormenorizada de sus ideas en "La recension crétoise des Argonautiques d'Apollonius", RHT 2, 1972, pp. 171-195 y un resumen en F. Vian-E. Delage, Apollonios de Rhodes. Argonautiques I. Chants I-II. Texte établi et commenté par F. V. et traduit par E. D., Paris 1974, pp. L-LII; viase también la opinión de H. Fraenkel, "Die Handschriften der Argonautica des Apollonius von Rhodos", Nachrichte'n von der Ge'sellschaft der Wiss. zu Göttingen Phil.-hist. Kl., 1929, pp. 164. 194 e fdem, Einleitung zur kritischen Ausgabe der Argonautika des Apollonius von Rhodos (Abhandl. d. Akad. d. Wiss. zu Göttingen Phil.-hist. Kl., III, 55), Gotinga 1964, pp. 55-91 (hay una traducción parcial ital. con el título Testo critico $e$ critica del testo, Florencia 1969).

9 Véase A. Franceschini, Giovanni Aurispa e la sua biblioteca. Notizie e documenti, Padua 1976 sobre la biografia y mss. de este personaje.

10 Estas obras debieron ser Las Argonáuticas de Apolonio, Los Fenómenos de Arato y Las Argonáuticas de Orfeo (sobre la historia del texto de este último poema véase lo que se dice en G. Dottin, Argonautiques d'Orphée, París 1930, y en el reciente artículo de F. Vian, "La tradition manuscrite des Argonautiques orphiques", RHT 9, 1979, pp. 1-46). 
el resultado, pues, fue nuestro $\Sigma$ III 3 , ff. $78-175^{\vee}$ en el que Damilás copió, además, los ff. 30-77* (Arati Phaenomena con escolios [ff. 30-53] y Argonautica orphica [ff. 54-77v]). "Tandis que Damilas copiait les Argonautiques -apunta Vian "- l'un des ses compagnons d'atelier confectionnait un corpus de scholies indépendent du texte à partir des scholies marginales de $k "$ (= protocretensis) ${ }^{12}$ y una tercera mano añadió en

11 Vian-Delage, o. c., p. LI. Una descripcion del Escorialensis 2 III 3, con cierto detalle, se da en Vian, «Recension crétoise», p. 173 y, tras un estudio de las diversas filigranas, este autor llega a la conclusión de que se trata "dans tous les cas d'un papier vénitien des années 1482-1493». Este mismo ms. tiene una curiosa característica que comparte con el T II 13 (152), también de M. Dándolo y copiado por A. Damilás como hemos dicho; tanto Revilla, o. c., p. 487 cono, ya antes, A. Adler, "Catalogue supplémentaire des manuscrits grecs de la Bibliothèque Royale de Copenhague. Aves un extrait du Catalogue des manuscrits grecs de l'Escurial rédigé par D. G. Moldenhawer», Det Kgl. Danske Videnskabernes Selskabs. Skriftu'r 7. Raekke, Historik og filosofisk Afdeling, II, 5, 1916, pp. 352-353 y, más tarde, Harlfinger, Aristoteles Graecus, p. 162 han dado noticia de los ff. en latín que acompañan al códice T II 13 tanto en su principio como final. "In IV autem membranaceis foliis - consigna Moldenhawer ap. Adler o. c. - sec. ut videtur XIV circa medium exaratis, quae ab utroque codicis operculo ligneo bina et bina eidem assuta sunt, habentur Ep. Latinae pro ea aetate inelegantissimac ad Anonymos, anonymo item auctore, qui nunc Malausana seu Malausane, nunc e Fonte Georg : : : nunc ex Avenione scribit. In his altera est ad Dionysium quendam Florentinum ut videtur gratulatoria quod a Roberto Rege (Neapolitano ut puto, qui ad a. 1343.. decessit) accersitus ad familiaritatem fuerit». Examinando el $\Sigma$ III 3 , hemos podido apreciar que hay $\mathrm{ff}$. de esta misma correspondencia pegados a las pastas do madera del ms., lo que no resulta del todo raro habida cuenta de que ambos códices pertenecieron al mismo personaje: Mateo Dándolo.

12 Los problemas que plantea el protocretensis son muy complicados (véasc Vian, "Recension crétoise» en general); uno de ellos consiste en las posibles relaciones con el Laurentianus XXXII, 16, el Soloranus de Fraenkel (bibliografía abundante sobre él especialmente en A. Turyn, Dated Greek Manuscripts of the thirteenth and fourteenth centuries in the libraries of Italy, I, Urbana-Chicago-Londres 1972, pp. 28-39 [con láminas $16-23$ en tomo II de la o. c.]), que fue comprado por Francisco Filelfo en Constantinopla en 1423 a la viuda de Juan Crisoloras y utilizado después, muy posiblemente, por Ángel Poliziano (†1494), así como por Jano Láscaris (1445-1534) que dejó notas de su puño y letra en algunos ff. El carácter planudeo de este ms. resulta indudable y las explicaciones al hecho de que Aristóbulo Apostolidis pudiese disponer de él o de copias no se han hecho esperar; como señalan Vian-Delage, o. c., p. LXIII, ya Gallavotti en SIFC 11, 1934, pp. 297-299 y en su edición de Teócrito de 1958, pp. 267-268, así como otros autores, indicaron que Aristóbulo copió en Creta un Teócrito planudeo en 1487 y que Triclinio utilizó directamente a Planudes para los escolios de Arato (véase J. Martin, Scholia in Aratum vetera, Stuttgart 1974, pp. XXIX-XXXIII), lo que prueba lo accesibles que eran los mss. de este último erudito. El corpus poético contenido en el Soloranus es muy variado, Apolonio, Arato, Nonno, Teócrito, Opiano, Nicandro. Hesíodo, etc. y una copia de él, según parece, fue realizada en 1465 por Constantino Láscaris en el Matritensis BN 4691 (N 61) que describe J. Iriarte, Regiae Bibliothecac Matritensis codices graeci manuscripti, I, Madrid 1779, pp. 201-223 y del que habla J. M. Fernández Pomar, «La colección de Uceda y los manuscritos griegos de Constantino Láscaris», EMERITA 34, 1966, p. 228. F. Piñero Torre, Estudios sobre el texto de los Argonauticos de Apolonio, tesis doctoral de la Fac. de Filosofía y 
ff. 2-9v las obras de Nicandro Theriaca y Alexipharmaca ${ }^{13}$, con lo que el $\Sigma$ III 3, testimonio de interés como hemos dicho, quedó completo.

La vinculación de Arsenio con el texto de Apolonio en particular - a la que hemos aludido- y con el corpus contenido en el $\Sigma$ III 3 es clara; con la excepción de Arato, el Bruxellensis 18.170-73, que fue copiado en marzo de 1489 por Arsenio, posee todo lo que contiene el Escorialensis ${ }^{14}$ y fue, además, copiado de éste. Por otro lado, del Bruxellensis el mismo Arsenio copió en Creta, en diciembre de 1491, el Sinaiticus $1194^{15}$ cuya copia fue complementada con un nuevo modelo, el Estensis gr. 112 (realizado entre 1485 y 1489, según es opinión general, por Alejandro Chomatas) ${ }^{16}$, que, a su vez, había sido copiado del

Letras de la Univ. Complutense de Madrid 1974 (inedita) ha mantenido, no obstante, la independencia del Matritensis respecto del Soloranus, pero sus argumentos, tanto codicológicos como críticos, no parecen desautorizar la opinión de Vian-Delage, o. c., p. XLIX, que compartimos: "cette copie offre l'intérêt de faire connaître un etat ancien de S[oloranus] et d'en faciliter la lecture; il comporte quelques conjectures de $\mathrm{C}$. Lascaris et des variantes introduites en général de seconde main par collation d'autres manuscrits». El códice español, según J. Martin, Histoire du texle des Phénomènes d'Aratos, París 1956, p. 243, en lo que a este texto se refiere, es gemelo del Borbonicus Neapolitanus II F 48 (del s. xv), cosa a la que Piñero Torre se opone igualmente. En lo que toca al $\Sigma$ III 3 y a su texto de Arato, diremos aqui que Martin, Histoire, pp. 231-234 lo estudia y que R. Browning, "Recentiores non deteriores", BICS 7, 1960 (= D. Harlfinger [ed.], Griechische Kodikologie und Textiiberlieferming, Darmstadt 1980, p. 268) encarece su importancia.

13 Véase, en general, A. S. F. Gow-A. F. Schollield, Nicander. The poems and poetical fragments. Eitited with a translation and notes, Cambridge 1953 (hay reimpresión) con bibliografía e información sobre la historia del texto; fundamental es el aparato crítico que presenta $\mathrm{O}$. Schneider, Nicandrea, Leipzig 1856 v de interćs resulta el trabajo de R. Fontán Barreiro, Estudios sobre la tradición matitserila de Nicandro. Tesis de Licenciatura de la Fac. de Filosofia y Letras de la Univ. Complutense de Madrid 1976 (inédita), pp. 86-128.

14 Para hablar con más precisión, no encontramos en este ms. el corpus de escolios que el Escorialensis tiene, pero Vian-Delage, o. c., p. LII señalan que Aristóbulo transcribe una buena parte de los escolios marginales de $k$ hasta I 770 y a partir de aqui una segunda mano continúa la tarea, aunque con muchas lagunas. Sobre los escolios, en general, véase la introducción de C. Wendel, Scholia in Apollonium Rhoditum vetera, Berlin 1935.

15 Véase, en general, G. Giangrande, "Eine unerforschte Handschrift des Apollonios Rhodios" en Studia Codicologica, pp. 227-230. Conviene destacar aquí que, por desgracia, la información codicológica y paleográfica que suele extracrse de trabajos de índole crítica es escasa y que muchos estudiosos siguen pensando que detalles de este tenor son meros adornos: un ejemplo, entre otros, es el trabajo de G. R. McLennan, "A uncollated manuscript of Apollonios Rhodios", MPhL 1 , 1975, pp. 33-36 que considera un ms., el Codex Alexandrinus 325, que whas apparent. lv never been collated, and was unknown to Fränkel. The ms. - continúa el autor en r. 33- has no date, but was probably written c. 1500". Una breve indicación codicológica - si fuese posible- o una lámina nos serían muy útiles, tal vez, a la hora de desenredar la madeja de escribas y mss. que en el filo de ambos siglos, XV y XVI, se dan cita en torno al texto de Apolonio.

16 La opinión de Gamillscheg-Harlfinger, o. c., p. 300 es contraria a esta identificación; para ellos, se trata de una copia realizada por Jorge Alexandru, copista 
mencionado Escorialensis ${ }^{17}$. Los códices de Apolonio en El Escorial no son numerosos ${ }^{18}$, únicamente dos más, pero era lógico pensar -aunque sólo fuese como hipótesis de trabajo- que alguno de ellos se relacio-

vinculado también al círculo de los Apostolios (véase Wittek, "Pour une étude", p. 292). Sobre él hay información en Vogel-Gardthausen, o. c., p. 70, Patrinelis, o. c., p. 68, Harlfinger, Die Textgeschichte, p. 408 y, en especial, Gamillscheg-Harlfinger, o. c., pp. 300-301; láminas encontramos en M. Sicherl, Die Handschriften, Ausgaben und Uebersetzungen von Iamblichos De mysteriis. Eine kritisch-historische Studie, Berlín 1957, lám. VIII, Harlfinger, Specimina, lám. 57, 1dem, "Zu griechischen Kopisten und Schrifstilen des 15. und 16. Jahrhunderts" en La paléographie grecque et byzantine (Colloques Internationaux du Centre National de la Recherche

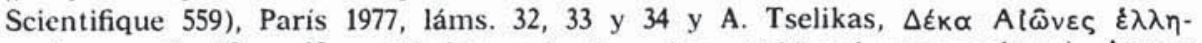

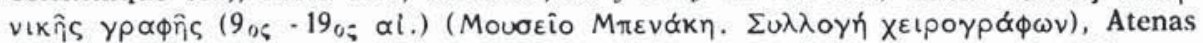
1977, lám. 18. De Andrés no recoge ningún ms. escorialense como obra de este amanuense aunque en Catálogo, III, p. 342 da cuatro códices a nombre de un tal Jorge. El primero de ellos, R I 19 (19), ff. $42-47$ es un membranaceus del s. XIV (véase Revilla, o. c., pp. 68-70) que, obviamente, nada tiene que ver con estos copistas de los siglos Xv a XVı (mención de él, aunque sin identilicación del copista, en S. Bernardinello, "Giorgio, un copista greco del xiv secolo", Annali della Facoltà di lettere e filosofia (Firenze) 1, 1976, pp. 34 y 37); el segundo, Y I 11 (250), fue identificado por nosotros (véase "Varia palaeographica graeca II", Habis, en prensa) como obra de Jorge Cocolo (Koко入ós); $\psi$ IV 24 (498), ff. 172-201v, el tercero, es un ms. del xıI1-xIV (véase De Andrés, Catálogo, III, pp. 111-113) y, finalmente, el cuarto, Y III 14 (284), ff. 188-241v, del a. 1486 (véase De Andrés, Catálogo, II, pp. 161$164)$ es el único que podria ser de Jorge Alexandru: hemos examinado el ms. en cuestión y, aunque no hemos llevado a cabo un estudio exhaustivo, podemos decir que su letra no es la de Jorge Alexandru ni la de Jorge Cocolo, Jorge Trivizias, Jorge de Constantinopla ni Jorge Gregorópulo, por citar algunos copistas de este nombre bien conocidos. Harlfinger, Die Textgeschichte, p. 408 y Aristoteles Graecus, p. 174 señalan en El Escorial, como obra de este copista, el Y III 10 (280), ff. 38-47v v 107-126v. Para un estudio del Estensis $\mathrm{gr}$. 112, ms. que ha motivado esta nota, véase Vian, "Recension crétoise», pp. 174-175.

17 Hay que destacar que las copias de Aristóbulo Apostolidis, hechas en Creta, sirvieron a su vez como modelo de una serie de mss. conocidos bajo la denominación de mss. de tipo D (véase G. Speake-F. Vian, "The so-called D-Manuscripts of Apollonius", GRBS 14, 1973, pp. 301-318), cuatro de los cuales (Parisinus gr. 2729 [a. 1490-1510], Vaticanus gr. 1358 [ca. 1505], Vaticanus gr. 37 [ca. 1491-1514] y Casanatensis 408 [G.III.5] [1490-1510]) fueron copiados por Demetrio Mosco, copista de quien ya hemos identificado mss. en España (véase nuestro trabajo «Varia palaeographica graeca III» de próxima publicación); uno de los códices de este grupo es obra de Miguel Suliardo y otros dos son de copistas inidentificados. En general, sobre este último copista mencionado, Suliardo, véase Vogel-Gardthausen, o. c., pp. 318-320, Patrinelis, o. c., p. 108 y Omont, o. c., lám. 38; colaborador del círculo de Miguel Apostolio, en España, según señala Harlfinger, Die Textgeschichte, p. 416 y Aristoteles Graecus, p. 180, tenemos de su mano el Escorialensis $\Omega$ IV 22, ff. 133 $138^{\mathrm{v}}$ únicamente, al que hay que añadir lo firmado por él en la B. N. de Madrid, según señaló ya en su catálogo Iriarte y recogen Vogel-Gardthausen, o. c., p. 319.

18 Referencias a los mss. de Apolonio del s. xv en G. Pasquali, Storia della tradizione e critica del testo, Florencia $1962_{2}$, p. 61 y lista en R. R. Bolgar, The classical Heritage and his beneficiaries, Cambridge 1954, pp. $494-495$ (véase, en general, la bibliografía citada en n. 8 de este trabajo). Según el inventario que presenta Franceschini (n.os 37 y 514), Aurispa poseyó dos códices de Apolonio que «potrebbero essere copie tratte dall'A[urispa], forse separando le opere di Apollonio 
nase de la manera que fuese con el hijo de Miguel Apostolio y, efectivamente, así es como sucede. El $\Sigma$ III 20 (119) ${ }^{19}$, que en los ff. 1-119v contiene las Argonauticas del de Rodas, es un códice de los que pertenecieron a Antonio Eparco ${ }^{20}$ que fue escrito, precisamente, por la misma

Rodio da quella di Eschilon, es decir, sacadas del famoso XXXI1, 9 (los dos mss. que de Esquilo poseyó Aurispa son los n.os 18 y 452 del inventario); pero hay que anadir que este mismo personaje compró en Roma, en 1456, otro códice del poeta de Rodas (Wolfenbiättel 2996 [Aug. 4. 10.2]), ms. del s. xiv obra de Pedro Crético (wéase, en general, sobre este copista, E. Gamillscheg, "Beobachtungen zur Kopistentaitigkeit des Petros Kretikos", JOB 24, 1975, pp. 137-145) que, muy probablemente, pasó a la colección de Guarino Veronese (véase Bolgar, o. c., p. 494 y, en especial A. Diller, "Greek codices of Palla Strozzi and Guarino Veronese", Journal of the Warburg and Courtauld Institutes 24, 1961, pp. 317-321 y Franceschini, o. c., p. 66): la historia de este códice y una excelente descripción con una lámina (n." 19) ahora en Griechische Handschriften und Aldinen. Eine Ausstellung anlässlich der XV. Tagung der Mommsen-Gesellschaft in der Herzog August Bibliothek Wolfenbiittel. Die Handschriften ausgew'ïhlt und beschrieb'n von D. Harlfinger in Zusammenarbeit mit J. Harlfinger und J. A. M. Sonderkamp. Dic Aldinch atusgewählt und crläuterl von M. Sicherl, Wolfenbüttel 1978, pp. 56-59. Pertenece este ms, a la segunda familia $(w)$ cuya cabecera comparte con el Solorantus y recibió, además, cierta influencia del protocretensis. Por lo que se refiere a la lista ofrecida por Bolgar, detectamos en ella ciertos errores; destacaremos aqui simplemente que el Riccardianus $53 \mathrm{~K}$ II 13 (ca. 1485) escrito por Juan Roso, según A. Olivieri, "Indici de'codici greci Riccardiani, Magliabechiani e Marucellianin, SIFC 2, 1894 (=Ch. Samberger [ed.], Catalogi codicum graecorum qui in minoribus bibliothecis italicis asservantur, I, Leipzig 1965, p. 170) no contiene Las Argonáuticas de Apolonio sino las de Orfeo.

19 Revilla, o. c., pp. 390-392 lo describe considerándolo como del s. xvi y descripción de él da también Vian, «Recension crétoise’”, pp. 190-191 quien piensa que fue copiado del Parisinus gr. 2727 (que es copia a su vez del Estensis gr. 112) cuanclo ya éste habia recibido una primera revisión.

20 Sobre este personaje véase, en general, E. Giotopulos-Sisilianos, "Avтóvtoc

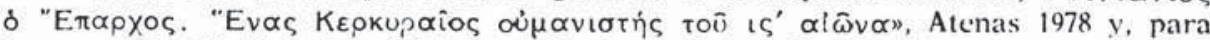
los mss. de El Escorial, básico es G. de Andrés, "La colección escurialense de mss. griegos de Antonio Eparcon, Scriptorium 15, 1961, pp. $107-112$ donde este códice aparece con el n." 12 del inventario (o. c., p. 110: "Apollonii Argonautica cum commentariis. Antiquissimusn) pero erróneamente como $\Sigma$ III 10. Es de destacar, por otro laclo, que Revilla ya habia identificado en su catálogo nueve mss. que formaban parte de la colección de Fparco y que, a pesar de la afirmación

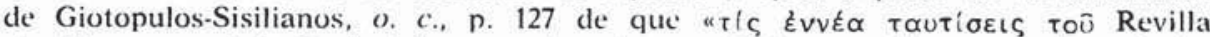
$\tau(\varsigma) \delta \varepsilon \chi \chi \varepsilon \tau \alpha \iota k \alpha(\delta$ De Andrés", conviene hacer ciertas precisiones ya formuladas en parte por esta misma autora. Fn primer lugar, Revilla, por ejemplo, identifici el $\Sigma 11120$ con el n." 11 de la "Relación de Guzmán de Silva» y con el mismo n." de "Libros de Eparco" (para los cinco inventarios que poseemos de los libros que Eparco poseyó, más uno fragmentario, véase De Andrés, "La colección escurialensen, p. 108) pero en la publicación de De Andrés no se respeta el orden de los inventarios como Giotopulos-Sisilianos, o. c., p. 127, n. 4 señala. En efecto, a los nueve identificados por Revilla, De Andrés añade 55 que se corresponden con 54 títulos, pero el "catálogo" que este autor publica no corresponde exactamente a ninguno de los inventarios existentes, sino que es una combinación del A. G. S (Archivo General de Simancas), Estado-Venecia, legajo 1594 (las tres últimas páginas), descubierto por el propio De Andrés en 1957 (véase "La colección escurialense», p. 5) y el A. G. S., Secretaria de Estado, legajo 1547, ff. 344-347v descubierto por 
mano que copió el $\Phi$ I 4 (182 ${ }^{21}$, y éste, según reza en el f. 1 de mano,

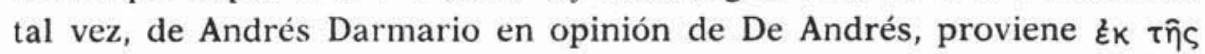

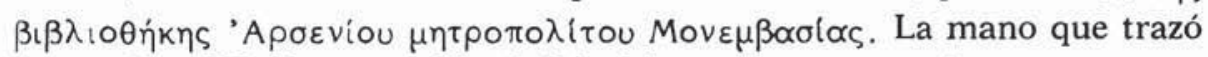
tanto el $\Sigma$ III 20 como el $\Phi$ I 4 lo hizo sobre un papel que comparte las filigranas de un áncora en círculo similar a Briquet n. ${ }^{\circ} 465$ (Venecia 1495) y una ballesta también en círculo muy parecida a Briquet $n .^{\circ} 746$ (papel italiano de la segunda mitad del s. xv), mientras que el $\oplus$ I 4 presenta además una escalera (Briquet n." 5920) que es de Venecia 1491-92 y Florencia 1494.

Sugiere Vian ${ }^{22}$ que el revisor del Sinaiticus 1194, ms. copiado en Creta por Aristóbulo Apostolidis en 1491 como hemos dicho, utilizó en alguna medida el Escorialensis $\Sigma$ III 20, pero esto, como es lógico, no nos aclara nada acerca de la cuestión que nos interesa estudiar; la única pista prometedora arranca del estudio pormenorizado de la letra del $\$$ I 4 y $\Sigma$ III 20 , letra que, sin lugar a dudas, es la de Zacarías Calliergis ${ }^{23}$. Efectivamente, dejando aparte por el momento la persona-

Revilla y conocido como "Libros de Eparco", y tanto en uno como en otro el $\Sigma$ III 20 aparece con el n. 11 (véase Giotopulos-Sisilianos, o. c., p. 302).

21 Véase descripción en De Andrés, Catálogo, II, pp. 5-6; el códice fue de A. Agustín, famoso prelado, a quien Andrés Darmario vendió bastantes mss. como es bien sabido. Ya en una venta realizada por el mismo mercader y copista a El Escorial en 1571 (véase Revilla, o. c., p. XXXVIII con un extracto de la lista del A. G. S., Secretaría de Estado, legajo 583, f. 72), De Andrés, Catálogo, II, p. 109 ha identificado como el n. 4 el Y II $5(260)$ del s. XIV que fue también de Aristóbulo Apostolidis pasando luego, antes de a Darmario, a manos de un tal Juan Codomneno. Las habilidades de Darmario para procurarse mss. le llevaron, si hemos de creer en estas informaciones, a toparse con los restos de la biblioteca del hijo de Miguel Apostolio. Decimos "si hemos de creer" ya que es de todos conocida la naturaleza de trápala y trapisondista que adornó al monenvasiota (véase, en general, alguna bibliografía sobre sus engaños en nuestro "Sobre un comentario anónimo a la Aritmética de Nicómaco de Gerasa y sus mss. en bibliotecas españolas», CFC 16, 1979-1980, p. 39, n. 42 y, como introducción general a la obra de este copista, la abundante bibliografia que $O$. Kresten, el especialista en este amanuense, recoge en "Der Schreiber und Handschriftenhändler Andreas Darmarios", Mariahilfer Gymnasium Jahresbericht 1967-1968 (= Harlfinger [ed.], Griechische Kodikologie, pp. 414-415).

22 «Recension crétoise», p. 191.

23 De un ductus "nicht ganz einheitlich", como señalan Gamillscheg-Harlfinger, o. c., p. 306, Bernardinello, o. c., p. 63, describiendo el códice 2302 (olim 216) de la Biblioteca Universitaria de Bolonia (de cuyo f. $87 \mathrm{v}$ ofrece una lámina, la n. 56 ). comenta su escritura con ciertas precisiones que, pese a su extensión, no nos resistimos a dejar de citar: "L'ascendenza più vicina - afirma este autor- è costituita dallo stile degli Odegi, al quale risale anche il Rosos. Con questo copista il Calliergi ha in comune il modulo e la forma del grande epsilon miniato come capolettera in questa tavola (per il Rosos cfr. Wilson, tav. 77): nel Rosos la lettera non è ortogonale, ma inclinata di $5^{\circ}$ e con un'aggiunta di ornato floreale più vistoso, barocco. Anche la maiuscola epigrafica dell'intitolazione è dello stesso tipo del Rosos (cfr. Omont, tav. 30; Wilson, tav. 77), ma nel Calliergi è più rielaborata 
lidad del copista, su relación con el texto de Apolonio y con la familia de mss. cretenses en particular es cosa bien probada. Vian ${ }^{24}$ ha estudiado el Riccardianus 35 (K II 17), copiado por el mismo Calliergis en Padua o Venecia, y señala que tuvo como modelo el Parisinus 2727, justamente el mismo modelo del $\Sigma$ III 20, "mais en donnant le plus souvent la préférence aux variantes notées par ses reviseurs"; Calliergis, pues, copió dos mss. de Apolonio, ambos del mismo modelo, y en ellos colocó una diferente dosis de las variantes añadidas que podían encontrarse en el códice sobre el que la copia fue hecha (por otro lado, el Riccardianus recibió también la influencia del Parisinus 2845). Como el Parisinus 2727 fue copiado en Creta entre los años 1487 y $1489^{25}$-tal vez por un copista del círculo- y el Riccardianus lo fue posiblemente en tierra italiana, parece lógico suponer que el $\Sigma$ III 20 fue copiado igualmente en Italia, Venecia o Padua, lugares donde Calliergis, como sabemos, pasó parte de su vida; veamos algunos detalles de su biografía.

Nacido en Creta (en Réthymnon exactamente) en torno al año $1473^{26}$, su primera obra datada, en opinión de Vogel-Gardthausen ${ }^{27}$, es el Matri-

con l'aggiunta di svolazzi più vistosi, analoghi a quelli della decorazione floreale del fondo dell'epsilon capolettera. Nella minuscola corsiva, inclinata di $30^{\circ}$, il beta ¿ di tipo maiuscolo, non a occhielli distanzati e senza che il tratto verticale si prolunghi molto sotto il rigo. Nel csi in quattro tempi il secondo tratto appare più marcato. Il rho chiuso e il phi presentano un apice a sinistra nell'estremità inferiore del tratto verticale. L'ipsilon e il psi sono dilatati in larghezza: il psi tende a legare con la vocale successiva il tratto orizzontale ondulato. Del theta ricorrono entrambe le forme, quella minuscola di regola nei legamenti, mentre del tàu sopra il rigo si hanno tre posizioni: isolato, con legamento inferiore ad arco normale, con legamento inferiore ad arco rovesciato, che si stacca ortogonalmente dall'asta verticale (riservato al legamento con alfa e con omega). Eccezionale e la presenza di un legamento Forma particolarissime assumono il sigma affine a una $S$ latina..., il $\kappa \propto l$ nel quale l'alfa ingloba il cappa, il nesso $\varepsilon v$ derivato dal $\mu \varepsilon v$ del Fettaugenmode, ma impiegato anche ad inizio di parola...”. La bibliografía fundamental es recogida por Gamillscheg-Harlfinger, $o$. $c$, a la que hay que añadir, ahora, las láminas 28 y $50 \mathrm{~b}$ de la obra colectiva ya citada Griechische Handschriften und Aldinen. Tanto en la parte copiada por A. Damilás en el $\Sigma$ III 3, como en el resto del ms., hay glosas interlineares y marginales de varias manos; en f. 159v, en concreto, aparece una que recuerda muy mucho el ductus del propio Calliergis, aunque es difícil opinar dados los pocos rasgos típicos de este copista que aparecen en la exigua cantidacl de escritura presente en los márgenes e interlíneas.

24 "Recension crétoise», p. 194.

25 Ibidem, p. 175.

26 Básico es el tratamiento que de la figura de este copista hace Geanakoplos, o. c., pp. 201-222. Algunas notas de interés en E. Follieri, "Il libro greco per i greci nelle imprese editoriali romane e veneziane della prima metà del cinquecenton en Venezia centro di mediazione tra Oriente e Occidente (secoli XV-XVI). Aspetti e problemi. A cura di H. G. Beck, M. Manoussacas, A. Pertusi (Civiltà Veneziana,

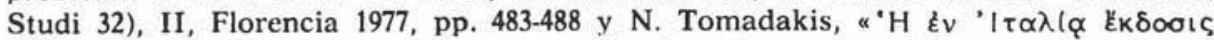

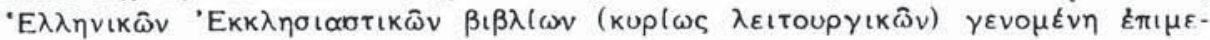


tensis BN 4564 (N 25) escrito el cinco de octubre de 1499, en Venecia ${ }^{28}$, para Nicolás Vlastos, editor, copista también ${ }^{29}$ y socio de Zacarías en trabajos editoriales; la atribución es errónea ciertamente, pero, aún

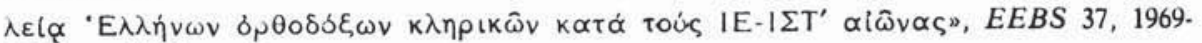
1970, pp. 3-33.

27 Véase Vogel-Gardthausen, o. c., p. 125.

28 Aparte de este testimonio de Vogel-Gardthausen citado, N. Wilson, «The book trade in Venice ca. 1400-1515" en Venezia centro di mediazione, 1I, pp. 394-395 habla del Matritensis como de "a product of his [de Zacarias] Venetian period, a relatively short part of his career» que, como senalan Gamillscheg-Harlfinger, o. c., p. 306 dura desde antes de 1473 a 1524 . Volviendo a las noticias que Vogel-Gardthausen dan, Fernández Pomar, $0 . c .$, p. 285 señala que en este ms. Constantino Láscaris copió los ff. 1-2v y $13-38$ en Mesina y nada más de interés nos dice aunque, como veremos, hay algunos problemas. En primer lugar, ya Iriarte, $0 . c .$, p. 121 afirmó que los dos primeros if. de la primera obra contenida en el $\mathrm{ms}$. son de Láscaris pero que luego siguen otros "non multùm absimili» para terminar el códice con una tercera mano "quae paulo vetustior videtur"; son tres, pues, los copistas y, dejando a un lado a Láscaris, el segundo de ellos copió los ff. 3-10v y el tercero los ff. 39.53. Nada tiene que ver con la letra de Calliergis la letra del último y el segundo de ellos, al menos en nuestra opinión, aunque no posee un ductus básicamente distinto, presenta las suficientes diferencias como para hacernos pensar que tampoco su letra fue trazada por la mano de Zacarías: la $\xi$ en nada se parece a la caracteristica del cretense, la $\pi$, de arquitos, es deforme, la $\beta$, las abreviaturas, en fin, muchos detalles difieren por lo que, a no ser que lo consideremos un producto tan temprano que la propia letra viene a ser prácticamente diferente, no podemos poner el ms. bajo la autoría de este copista. ¿Cómo, pues, se le atribuye $y$, lo que es más raro, se dan fechas concretas de su factura? La respuesta no deja de ser un tanto curiosa. En realidad, en la descripción que Iriarte da del ms. se contienen todas las causas del error; en o. c., p. 120 lo que el catalogador dice es que la praefatio de la obra de Simplicio sobre las Categorias de Aristóteles, que Láscaris copia, coincide con la edición que publicó no Aldo Manucio, como Fabricius dejó dicho en su Bibliotheca, sino Zacarías Calliergis para N. Vlastos

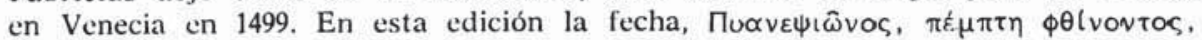
es traducida por Iriarte como "Julii die XXVI" mientras que Vogel-Gardthausen, cometiendo el error de suponer el BN 4564 obra de Calliergis como ya hemos dicho, interpretan "cinco de octubre»; la cuestión, aunque marginal, tiene cierto interés ya que M. Flodr, Incunabula classicorum, Amsterdam 1973, p. 63, recogiendo los datos de otros muchos catálogos, señala que los Hypomnemata in Aristoteles Cathegorias de Simplicio fueron editados por Zacarías Calliergis para Vlastos en Venecia el 27 de octubre de 1499. La cuenta de los días con una expresión como $\pi \dot{\varepsilon} \mu \pi \tau \eta \phi \theta i v o v \tau o s$ es antigua; J. D. Mikalson, The Sacred and Civil Calendar of the Athenian Year, Princeton 1975, pp. 8-10, estudió el tema y B. D. Meritt, The Athenian Year, Berkeley-Los Angeles 1961, p. 38, afirma que "was used in Athens officially down to the end of the fourth century B. C., the last example now known being from the year 306/5" (véase también A. E. Samuel, Greek and Roman Chronology. Calendars and Years in Classical Antiquity, Munich 1972, pp. 59-61). De todas formas, si el mes tiene 30 días se trata de un 26 y, si tiene 29 , la expresión $\pi \dot{\varepsilon} \mu \pi \tau \eta \phi \theta$ ivovtos indica un 25 de acuerdo con las tablas que Meritt publica $(o, c$,

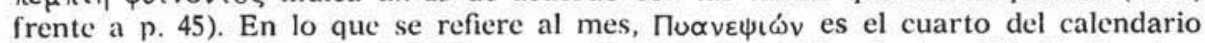
ático (véase también E. J. Bickerman, Chronology of the Ancient World, Londres 1968, p. 20, n. 1) cuyo orden normal comienza en el mes Hecatombaión que corresponde a julio-agosto, siendo aquél, por tanto, un mes que ocupa la segunda mitad de octubre y la primera de noviembre. Ha sido, no obstante, P. Tannery, «Les 
más temprano, en la edición aldina de Aristófanes (1498), ya se utilizó un ms. del Pluto obra de Calliergis (Selestadiensis 347$)^{30}$ y A. Turyn ${ }^{31}$ ha señalado, por otra parte, que el Vaticanus Palatinus gr. $319^{32}$, que contiene Esquilo, Sófocles y Eurípides, así como escolios a Teócrito y otras cosas, es obra en sus ff. 95-117 de Jorge Gregorópulo ${ }^{33}$ (suscripción del 5 de octubre de 1489), mientras que los ff. 189-259 fueron copiados por Aristóbulo Apostolidis y Zacarías Calliergis se encargó de los ff. 333-359. Si las diversas partes del volumen son coetáneas, esto representa una actividad muy temprana de nuestro copista y, a la vez, una colaboración estrecha con el círculo de escribas cretenses ${ }^{34}$ muy probablemente anterior a su primera ida a Italia ${ }^{35}$. Las labores de im-

noms de mois attiques chez les Byzantins", Revue Archeologique 3* s., 9, 1887, pp. 23. 36 (= Mémoires scientifiques, IV, pp. 223-239), quien ha estudiado y puesto en claro el uso que los bizantinos hicieron de los nombres áticos en su calendario, un uso algo complicado ya que el orden fue alterado según los diversos autores y algunos nombres cambiados; el calendario que gozó de más fama es el de Teodoro Gaza, descrito en un opúsculo de 1470 que fue impreso posteriormente. Los humanistas bizantinos lo imitaron y, como afirma V. Grumel, Traité d'études byzantines, I. La chronologie, París 1958, p. 177, «il est bien probable que les copistes, qui dans des souscriptions de manuscrits de XVIc siècle, emploient les noms de mois attiques, sont dans la même dépendance». Por todo ello y habida cuenta de que el calendario bizantino no difiere del romano sino por el hecho de que el principio del año está colocado en el primero de septiembre y porque los nombres de los meses, por puro arcaísmo, son los antiguos (así como porque el cómputo de los días se hace de acuerdo con los sistemas antiguos: suponiendo tres décadas en el mes), por todo ello - repetimos- tanto Iriarte como Vogel-Gardthausen parecen estar equivocados y la fecha 27 de octubre es la correcta ya que este mes, que equivale a $\Pi u \propto v \varepsilon \psi(\omega)$ en los Menologios y en el opúsculo de Gaza y sus seguidores, tiene 31 dias en el calendario romano prejuliano, en el juliano y en el bizantino. En suma, un error de fechas y otro de atribución a un copista que, por su interés, bien merecen el espacio que les hemos dedicado.

29 Véase Vogel-Gardthausen, o. c., p. 125 y un espécimen de su letra en Bernardinello, Autografi, lám. 40.

30 Griechische Handschriften und Aldinen, lám. 50 b (del f. 1); Sicherl comenta la edición citada en esta misma obra.

${ }_{31}$ The Byzantine manuscript Tradition of the tragedies of Euripides (Illinois Studies in Language and Literature, 43), Urbana, Illinois, 1957, pp. 355-356.

32 Véase Patrinelis, o. c., pp. 69 y 89.

33 Sobre este copista, colaborador en las tareas de impresión de Calliergis, hablaremos detenidamente más adelante.

34 Por cierto que, según Turyn, Byzantine manuscript Tradition, pp. 343-344, este Vaticanus está emparentado, por su texto, con el Mosquensis 508, también del s. XV. que perteneció a Juan Bautista Rasario, personaje veneciano (1517-1578) del que tendremos ocasión de volver a hablar.

35 Otra pista interesante para las actividades primitivas de Zacarías representa el Escorialensis $\Omega$ I 9 (510), ms. del que Turyn, Byzantine manuscript Tradition, p. 365, afirma que fue copiado del Parisinus 2712; fue el propio Calliergis quien copió de este Parisinus la parte de Sófocles en el Florentinus Riccardianus 34 (véase Vogel-Gardthausen, $O$. c., p. 125 y Turyn, "The Sophocles recension of Manuel Moschopulus", TAPhA 80, 1949, p. 148 ss.); recordemos que otro Riccardianus, el 
presión en este país, al menos en su primera etapa, no duraron mucho; la sociedad con Vlastos se fue pronto al garete y del 26 de octubre de 1499 al 12 de abril del año 1501 se piensa que Calliergis estuvo en Creta de donde regresó de nuevo a Italia con intención de llevar a su familia a Padua como, sobre bases documentales, ha señalado Geanakoplos ${ }^{36}$. Siguió copiando mss. en esta localidad ${ }^{37}$ y en 1509 , el 14 de abril, sabemos que apareció en Venecia un pequeño volumen con el título Exepsalmata al que siguió, meses después, el De officio regio de Agapeto ${ }^{38}$, que son exponentes de la reanudación de sus empresas editoriales. También en la ciudad de los canales su actividad impresora fue breve; "the unsettled political conditions and economic depression in Venice resulting from the War of the League of Cambrai - señala Geanakoplos ${ }^{34}$ seem to have been responsible for the closing of Calliergis' press, as had likewise happened in the case of Aldus" y Zacarías parece desaparecer de nuevo de la faz de la tierra hasta 1515 en que le encontramos en

n. ${ }^{\circ} 35$, es el ms. de Apolonio copiado por Calliergis que ya hemos mencionado. El Escorialensis citado, descrito por De Andrés, Catálogo, III, pp. 128-129, presenta una filigrana muy parecida a Briquet $n .746 \mathrm{y}$, precisamente, otra filigrana similar a ésta podemos ver en el Guelf. $71 \mathrm{Gud}$. gr. que Harlfinger describe en Griechische Handschriften und Aldinen, p. 80 , pero este autor señala que esta marca aparece en otros mss. de la colección de Wolfenbüttel que son del a. 1491 y que debieron ser escritos en Venecia o Padua ya, no en Creta. Por otro lado, el Holckham. gr. 85 (en Wilson, Mediaeval Grek Bookhands, lám. 84), que es de 1490, tiene la marca Briquet n. $465 \mathrm{y}$, precisamente, como vimos, éstas son las dos marcas, Briquet n.us 746 y 465 , que parecen estar presentes en los Escorialenses $\Sigma$ III 20 y $థ$ I 4. Si el Sinaiticus 1194 fue copiado por A. Apostolidis en Creta en el último mes del a. 1491 y, según Vian, su corrector se sirvió del $\Sigma$ III 20 (que, como el Riccardia. uuts 35, fue copiado del Parisinus 2727 escrito en Creta entre los años 1487 y 1489), nada impide pensar que ambos Escorialenses sean contemporáneos; en cuanto a su procedencia, Creta o Italia, nos movemos aquí en un terreno de suposiciones en el que es difícil pisar con seguridad.

36 Geanakoplos, o. c., p. 209.

37 El ms. 2302 de la BU de Bolonia fue escrito, según suscripción, en Padua (véase Aristoteles graecus, p. 64) y muy probablemente a principios de su estancia allí (entre 1501 y 1509 o bien 1515, como muy tarde, según E. Lobel, The Greek Manuscripts of Aristotle's Poetics [Suppl. to the Bibliogr. Society's Transactions, 9], Oxford 1933, p. 50). También, aunque sin fecha, tenemos el Parisinus gr. 2823 (véase Vogel-Gardthausen, o.c., p. 126 y Turyn, Byzantine manuscript Tradition, p. 216) dado por Lobel, ibidem, como escrito en Padua; fue en esta ciudad donde Calliergis colaboró con otro copista, de nombre Cunstantino Mesobotis (véase Geanakoplos, o. c., pp. 210-211 y Gamillscheg-Harlfinger, o. c., pp. 313-314), que sabemos que estuvo allí en 1508: fruto de esta colaboración, por ejemplo, es el Florent. Riccardianus 15 dado por Harlfinger, Aristoteles graecus, p. 356 como de en torno a 1500 .

38 En nuestro estudio "Dos traducciones de Agapeto impresas en el siglo XVI", $C B$, en prensa, consideramos diversos aspectos de la fortuna de este autor y, en especial, sus versiones por tierras españolas.

39 O. c., p. 213. 
Roma donde el 13 de agosto aparece su edición de Píndaro ${ }^{40}$ y su Frínico $^{41}$ ( 1 de julio de 1517). Una vez más perdemos la pista del copista e impresor hasta $1520^{42}$, fecha en que le volvemos a encontrar en la Roma eterna donde suscribió en 1524 el último ms. fechado que de él

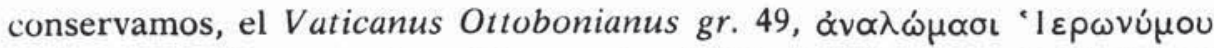

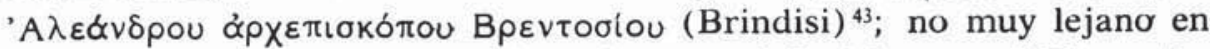
el tiempo, antes o después, debe colocarse el Parisinus gr. 2854 escrito

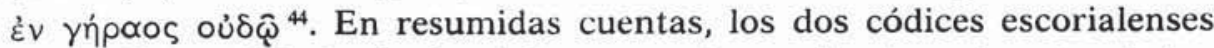
$\Sigma$ III 20 y $\Phi$ I 4 , de finales del s. xv ambos, a la vista de estos datos, tal vez fueron escritos en tierras italianas.

A lo que hemos consignado sobre la producción de este copista, podemos añadir algún dato más; hemos encontrado en El Escorial, en efecto, otros dos mss. copiados por Calliergis que no habian sido atribuidos a él que sepamos: se trata del $\Omega$ IV $7(559)^{45}$ y del $\Phi$ III 14 (233) ${ }^{46}$ los cuales, muy probablemente, fueron en un tiempo de A. Dar-

4. Véase un excelente estudio de ella en J. Irigoin, Histoire du texte de Pindare, Paris 1952, pp. 408-420; testimonio de su labor de copia en esta ciudad es el Cadurcensis gr. (Cahors, Maison des (Euvres diocésaines $81 \mathrm{~A}$ ) estudiado por J. Leroy, "Un manuscrit grec écrit à Rome: Le Cadurcensis graecus», Boll. dell'lstituto di Patologia del Libro "Alfonso Gallo" 30, 1971, pp. 135-146 (véase Kresten, Eine Sammlung von Konzilsakten aus dem Besitze des Kardinals Isidoros von Kiev [Oesterr. Akad. Wiss., Philos.-hist. Kl., Denkschriften, 123], Viena 1976, p. 58, n. 147, punto $m$ ).

${ }_{41}$ Véase E. Fischer, Die Ekloge des Phrynichos (Sammlung griechischer und lateinischer Grammatiker), Berlín 1974, p. 33; Zacarias, en su edición, sigue básicamente el Laurentianus VI, 22 escrito en 1491 por el conocido copista, que trabajó para Besarión, Juan Roso y otro códice de este autor, el Palatinus gr. 132, fue copiado por un tal Zacharidis (véase Fischer, o. c., p. 5) que más adelante volveremos a ver en relación con la familia Gregorópulo (véase n. 70).

42 Véase Geanakoplos, o. c., p. 219.

43 Véase Vogel-Gardthausen, o. c., p. 125 y Lobel, o. c., p. 50.

44 Véase Vogel-Gardthausen, o. c., p. 126 y lám. 49 (del f. 46) de Omont, o. c. Esta suscripción nos recuerda la del Matritensis BN 4636, f. $191^{v}$ en la que Láscaris,

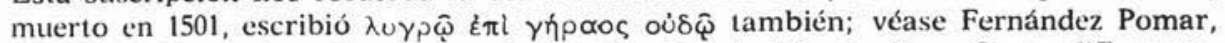
o. c., p. 221, n. 2 y Ch. Graux-A. Martin, Facsimilés de Mss. Grecs d'Espagne, París 1891, lám. XVIII, facs. 62.

45 Véase De Andrés, Catálogo, 1II, pp. 212-213; los ff. 104-127v y 142-165v están escritos por Calliergis mientras que una letra, ciertamente parecida pero mucho menos cuidadosa $y$, en nuestra opinión, diferente, llevó a cabo, en el mismo papel que la anterior, los ff. 128-141. La letra que copió los ff. 1-104 de este códice es la misma, sin lugar a dudas, que realizó los ff. 1-154 del BN 4806 (O 87) como hemos podido comprobar y hasta el papel es similar al empleado en el ms. de El Escorial. En este segundo códice citado, que también fue de Darmario según parece, hay otras letras de las que no nos ocuparemos aquí.

46 Véase De Andrés, Catálogo, II, p. 68; contiene este ms., entre otras cosas, algo de Demetrio Mosco, copista y autor ya citaclo y vinculado al círculo de A. Apostolidis con quien, según Speake-Vian, o. c., p. 309 , no es difícil imaginar que Mosco se relacionase, aunque "unfortunately, there is no evidence other than

$\mathrm{LI}, 10^{\circ}-8$ 
mario, aunque, como es natural, no faltan dudas acerca de sus otros poseedores. Así, el segundo de ellos, según De Andrés, perteneció, antes de ser de Darmario, a la colección de Antonio Eparco ${ }^{47}$, en cuyo inventario lleva el n." 27, Manueli Moschopuli Erotemata. Liber antiquissimus; Giotopulos-Sisilianos, sin embargo, manifiesta sus reparos sobre este punto ${ }^{48}$, al tiempo que expone sus dudas sobre la correcta identificación, entre los libros que pertenecieron a Eparco, del R I 12 (12), $\Sigma$ I 1 (61), y III 9 (332) y, finalmente, $\Omega$ II 7 (524).

Si pasamos ahora al R I 16 (16) ${ }^{49}$, el tercer ms. de Apolonio del Real Monasterio, su copista, a primera vista, muestra un cierto parecido con la mano que copió los ff. $12-53$ del Y III $7^{50}$, mano que es identificada por Harlfinger ${ }^{51}$ como la de Manuel Rusotas ${ }^{52}$, pero existen diferencias que nos han obligado a extender nuestra investigación hasta encontrar algo más parecido. En nuestra opinión, la mano que copió el R I 16 es la misma que escribió el Matritensis BN 4714 (O 49) que ha sido atribuido, falsamente desde luego, al copista Jorge de Constantinopla. De los diez mss. que en el repertorio de Vogel-Gardthausen ${ }^{53}$ se recogen como copiados por este Jorge, hay tres que hoy día se encuentran en nuestra Biblioteca Nacional. El primero de ellos, el Matri-

textual for a connection» (ibidem, n. 13). Calliergis copió por entero el ms. del que hablamos.

47 "La colección escurialense», p. 110.

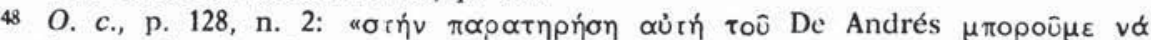

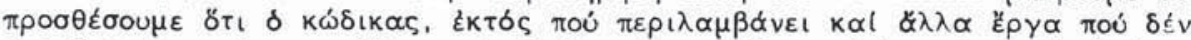

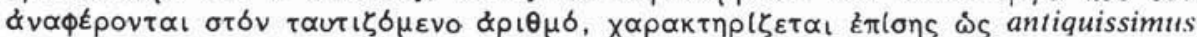

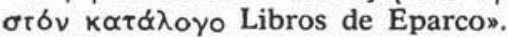

49 Véase Revilla, o. c., p. 64; el ms., que no parece tener marcas de papel, comparte con el $\Sigma$ III 21 (véase n. 62) su pertenencia a Juan Bautista Rasario "subdito de S. M.d, en el estado de Milán» (véase Graux, Essaie sur les origines du fonds grec de l'Escurial [Bibliothèque de l'Ecole des Hautes Êtudes. Sciences philologiques et historiques, 46], París 1880 [hay reimpresión], p. 115, n. 2) que estuvo en contacto con Guzmán de Silva, embajador de Felipe II en Venecia y uno de sus proveedores de libros, así como con Juan Páez de Castro, el cardenal de Burgos e incluso D. Diego Hurtado de Mendoza (véase Graux, o. c., pp. 114, n. 3 y 118, n. 3), a algunos de los cuales procuró mss. griegos de aquellas tierras. Como testimonia Graux, basándose en los documentos originales (o. c., p. 120, n. 1), Antonio Gracián, desde Madrid, escribe a Guzmán de Silva el 25 de febrero de 1572 que le encargue libros a Rasario. Véase también M. E. Cosenza, Biographical and bibliographical Dictionary of the Italian Humanists and the World of Classical Scholarship in Italy 1300-1800, Boston, Mass., 1962-1967, tomo IV, pp. 3004-3005.

50 Descripción excelente en Harlfinger, Aristoteles graecus, pp. 170-172.

51 Ibidem, p. 171.

52 Fue colaborador, probablemente en Venecia, de Jorge Trivizias y, en Vicenza, a finales del s. Xv, de Manuel Gregorópulo, copistas de los que hablaremos más adelante; bibliografía básica en Gamillscheg-Harlfnger, o. c., p. 309 y una lámina ofrece Harlfinger, Griechische Handschriften und Aldinen en p. 76.

53 O. c., pp. 79-80; nada hay en los suplementos a este repertorio que se refiera al copista de Constantinopla. 
tensis BN 4714 citado $^{54}$, que fue de "Jacobi Hurtadi Mendoza Iliberitani et Antonii fratris", del s. XVI según De Andrés, perteneció al cardenal de Burgos, pero no está escrito en modo alguno por Jorge de Constantinopla ${ }^{55}$. Sí son de él, en cambio, los Matritenses BN 4591 (O 1) y 4592 $(\mathrm{O} 2)^{56}$ de los que el primero fue escrito, según De Andrés, en torno al año 1547 , mientras que el segundo, por mano del propio copista, sabemos que fue copiado en este mismo año ${ }^{57}$. En definitiva, la letra del R I 16 y BN 4714 es, sin lugar a dudas, la misma ${ }^{58}$, nada tiene que ver con la de Jorge de Constantinopla y, por último, puede ser puesta en relación con otra letra que, dentro del estilo de "letra humanista" - a cuyo primer grupo, la llamada "Sguropulos-Schrift", pertenece igualmente la de Rusotas - ha sido estudiada por Harlfinger ${ }^{59}$; nos referimos a la de Pedro Hypsilás ${ }^{\infty}$, natural de Egina y colaborador de Demetrio Chalcondylas $^{61}$ con cuyo ductus guarda también un cierto parecido. Copió Hypsilás mss. en Milán, datados a partir de 1497 y, como señalan Gamillscheg-Harlfinger, "zwei Varianten seines Duktus sind zu unterscheiden" ${ }^{62}$.

\$t Véase E. Miller, Bibliothèque Royale de Madrid. Catalogue des manuscrits grecs (Notices et extraits des mss. de la Bibliothèque Nationale et autres bibliothèques, XXXI, 2 [1886], pp. 1-116), pp. 86-87 y G. de Andrés, "Historia de un fondo griego de la Biblioteca Nacional de Madrid. Colecciones Cardenal Mendoza y García de Loaisa", RABM 77, 1974, pp. 33-34. La indicación de posesión en el f. 1, a que hace alusión Miller, ha desaparecido hoy junto con el f. y la afirmación de VogelGardthausen de que fue escrito el 28 de abril de 1548 no es correcta.

55 Este copista, por otra parte, fue uno de los que trabajaron para el cardenal según señala Graux, o. $c .$, p. $68, \mathrm{n} .1$ y veremos a continuación.

56 También del cardenal; véase De Andrés, "Historia de un fondo", pp. 30 y 31 y notas en G. Mercati, "Il codice messinense del Doxopatres" en Per la storia dei manoscritti greci di Genova, di varie badie basilitane d'Italia e di Patmo (Studi e Testi, 68), Ciudad del Vaticano 1935, pp. 65-66.

57 Hemos identificado media docena de códices escritos por este copista en el fondo escorialense de Hurtado de Mendoza, pariente del cardenal, de los que damos noticia en nuestro "Manuscritos griegos de El Escorial copiados por Jorge de Constantinopla», RUC, 1981 [1983], pp. 374-376.

58 Aparte de otras coincidencias codicológicas, conviene destacar que ambos códices tienen reclamantes verticales subrayados en rojo mediante una especie de llave muy adornada que los contiene.

59 "Zu griechischen Kopisten", p. 335 ss.

60 Véase sobre él Gamillscheg-Harlfinger, o. c., p. 320 y un espécimen de su letra en Omont, o. c., lám. 44; un fragmento de esta misma lámina en E. M. Thompson, A Handbook of Greek and Latin Palacography, Londres 1901 (hay reimpresión), p. 178.

61 Copista también estudiado por Harlfinger, "Zu griechischen Kopisten» y Die Textgeschichte, pp. 224 ss. y 410 con ejemplos de su letra en Omont, o. c., lám. 16, Harlfinger, Die Textgeschichte, lám. 22, "Zu griechischen Kopisten», lám. 15 y Bernardincllo, Autografi, lám. 59.

62 Por otro lado, hay que destacar que parece existir una cierta relación indirecta entre este copista y el círculo de amanuenses que colaboraron en torno a 
Si queremos seguir buscando una relación con Aristóbulo Apostolidis, debemos plantearnos ahora la identidad del copista de los ff. 2-9v

Aristóbulo Apostolidis ya que un ms. copiado por Hypsilás, el Vaticanus Palatinus 277 , contiene el mismo corpus de retórica que el $\Sigma$ III 15 - sobre el que hablaremos más adelante-, el mismo que el Oxoniensis Auct. T.3.13 copiado por Jorge Alexandru, que el Cantabrigensis Queen's C.33 (20), ff. 1-140v de un tal Nicolás (véase sobre él Gamillscheg-Harlfinger, o. c., p. 318), colaborador de Jorge y Manuel Gregorópulo y del propio Zacarias Calliergis y, finalmente, que el Vindobonensis Phil. 60 obra de Jorge Trivizias quien, precisamente, se relacionó personalmente con Antonio Damilás como muestra el códice Laurentianus LVI, 14 escrito no por Trivizias sino posesión suya según ha demostrado E. Mioni, "Bessarione scriba e alcuni suoi collaboratori" en la Miscellanea Marciana di studi Bessarionei (a coronamento del $V$ centenario della donazione nicena), Padua 1976, p. 311 contra la opinión de Vogel-Gardthausen, o. c., p. 85 (de Trivizias hemos identificado ya el Burneianus 94 al hablar de los mss. que pudo poseer el Deán Martí en nuestro "Varia lexicographica graeca manuscripta IV: lexica medican, Helmantica, en prensa, n. 38 y otro códice en nuestro artículo citado en n. 17: precisamente el Escorialensis $\Sigma$ III 21 que es uno de los dos de Rasario que conservamos en El Escorial [véase nn. 34 y 49]). Si nuestra suposición es exacta y - de acuerdo con el análisis paleográficofue Hypsilás quien copió tanto el R I 16 como el BN 4714, tendríamos entonces, en primer lugar, que otro $\mathrm{ms}$. de Apolonio (R I 16) fue escrito por un copista "próximo" al círculo de A. Apostolidis cuyos miembros copiaron otros muchos como ya hemos visto. En segundo lugar, constataríamos simplemente que, en un tiempo, Rasario poseyó dos mss. (R I 16 y $\Sigma$ III 21) escritos por dos copistas "relacionados» con el círculo de Aristóbulo y tal vez - eso no lo sabemos- entre sí $y$, finalmente, no tendría nada de raro encontrar en el fondo del cardenal de Burgos un ms. de Hypsilás (BN 4714), el único a lo que parece, cuando uno de sus proveedores de libros en Italia, el mencionado Rasario, ya tenía otro comprado tal vez en el mismo lote que los dos anteriores códices citados y procedentes, los tres, de ambientes "relacionados" con los miembros del taller de A. Apostolidis. Nos queda únicamente referirnos al $\Sigma$ III 15 (114), ms. que hemos citado en relación con el corpus retórico al que aludíamos y del que Revilla, o. c., p. 370, no identifica a su copista. $\mathrm{Si}$ los presupuestos que manejamos tienen alguna verosimilitud este códice debería ser de alguien relacionado con el círculo aludido y, en efecto, tras un examen del ms. no tenemos la menor duda de que ha sido escrito por el propio Aristóbulo; por si esto fuera poco, este códice perteneció a M. Dándolo, igual que otros varios que ya hemos mencionado en este trabajo (De Andrés, Catálogo, III, p. 343 lista bastantes de él, más de 40 como ya hemos dicho) y si quisiéramos proseguir un poco más allá nuestras investigaciones, ojeando simplemente los códices de este personaje, encontraríamos, por ejemplo, que el Ф II 9 (206), escrito en su mayor parte por Antonio Damilás en Creta en 1489, presenta en ff. 1-10 una mano desconocida que De Andrés no identifica (Catálogo, II, p. 36); pues bien, esta mano es, también sin la menor duda, la del propio hijo de Miguel Apostolio, Aristóbulo Apostolidis, que, como tendremos ocasión de ver más adelante, ha prodigado su letra colaborando con Damilás como hizo en el $\Sigma$ III $3, \mathrm{~ms}$. que ha dado origen a todas estas observaciones. Resumiendo, pues, es relativamente fácil advertir múltiples huellas de los copistas cretenses de los siglos XV-XVI relacionados con los Apostolios en mss. españoles, huellas hasta ahora no señaladas, y no es difícil darse cuenta, a la vez, de la importancia que para la vinculación de los diversos mss. con vistas a la realización de un stemma pueden tener estas observaciones. Por supuesto, en el caso de un texto bien estudiado como es el de Apolonio, este tipo de detalles no sirve sino para completar la visión general que se ha obtenido a partir de complicados análisis críticos; en otros 
del $\Sigma$ III 3 que copió parte de las obras de Nicandro ${ }^{63}$. Como ya hemos dicho, Wittek ${ }^{64}$ ha estudiado con detalle el taller de los Apostolios, de forma que es posible espigar entre sus miembros con vistas a encontrar algún amanuense cuyo ductus sea idéntico al del tercer escriba presente en el códice que ha dado origen a nuestra investigación; descartando nombres famosos como los de Demetrio Trivolis ${ }^{65}$, Manuel Atramyttino ${ }^{60}$, Tomás Bitzimano ${ }^{67} \mathrm{y}$ otros menos conocidos, nos quedamos con la familia de los Gregorópulo, colaboradores del círculo de los Apostolios, amigos y colaboradores también de Zacarías Calliergis

casos de textos con historias textuales menos obvias, las relaciones establecidas por la mera identificación de las letras y scriptoria pueden servir para una orctenación previa del material que lacilite los trabajos críticos.

63 Por ciertas omisiones en el texto nicandreo, el códice escorialense parece pertenecer al grupo PBV formado por el Parisinus Reg. 2728 (s. XV) que contiene Apolonio y Arato y fue escrito por Jorge Gregorópulo $(P)$, el Leidensis BU Perizonianus F 7 A que presenta también escolios a Apolonio y a Píndaro $(B)$ y parece ser obra de Demetrio Mosco y, finalmente, el Venetus Marcianus 480 ( $\mathrm{s}$. Xv también) que es una colección de poesía escrita por el conocido copista Juan Roso (véase Mioni, «Bessarione scriba», pp. 302-304) para Besarión ( $V)$. Véase sobre el ms. del Real Monasterio A. Crugnola, «Un codice inedito dei Theriaca di Nicandro (Escorial Ms. gr. $\Sigma$ III 3)n, Acme 16, 1963, pp. 73-85, autor que también se ha ocupado de $P$ en "Nuova collazione del codice Nicandreo P (= Paris. Reg. 2728)", ibidem, pp. 293 297. Martin, Histoire, p. 232 señala que el $\Sigma$ III 3, en la propia Creta, sirvió como modelo de $P$ y, refiriéndose al texto de Nicandro, este autor, ibidem, p. 234, precisa que fue copiado con toda seguridad del Escorialensis "comme le prouve l'absence des vers 681-692 et l'insertion absurde de quelques fragments de scholies qui sc trouvaient, par hasard, dans le modèle, en contact étroit avec le texte. D'unc façon générale, Gregoropulos copie tant ce qu'il trouve dans les colonnes intérieures du Scorialensis, et rien que celan.

ot Scriptorium 7, 1953, pp. 290-297 ya citado.

65 Véase, en general, A. Oleroff, «Démétrius Trivolis, copiste et bibliophile», Scriptorium 4, 1950, pp. 260-263 y bibliografía en Harlfinger, Specimina, pp. 21 y 22 , obra que edita dos láminas de su letra.

*6 Véase Vogel-Gardthausen, o. c., p. 116, Patrinelis, o. c., p. 67, Canart, «Scribes grecs", p. 72 y una prueba de su letra en Omont, o. c., lám. 19 y Mioni, Introduzione alla paleografia greca (Studi Bizantini e Neoellenici, 5), Padua 1973, lám. 28; ningún ms. de él ve De Andrés en El Escorial.

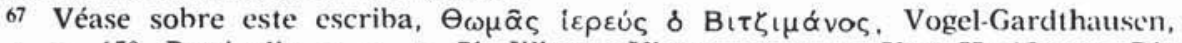
o. c., p. 150, Patrinelis, o. c., p. 71, Wiesner-Victor, o. c., p. 53 y Harlfinger, Dic Textgeschichte, p. 409, entre otros, y muestras de su escritura en Wittek, Album, lám. 41 y J. Bick, Die Schreiber der Wiener griechischen Handschriften (Museion. Veröffentl. aus der Nationalbibl. Wien, Abhandlungen, 1) Viena-Praga-Leipzig 1920, lám. L. Harlfinger ha señalado quc el Salmanticensis M 54 (1-2-6) es, en parte, suyo y sobre los problemas que este $\mathrm{ms}$. ha planteado a la investigación moderna hemos escrito ya en "La paleografía griega y los manuscritos de las bibliotecas españolas en los últimos años: acta atque agenda», Actas del VI Congreso Nacional de Estudios Clásicos, I, Ponencias, Madrid 1983, pp. 206-207. Para terminar, sobre algunas copias de Bitzimano en colaboración con A. Apostolidis, Miguel Apostolio, Demetrio Mosco, Manuel Gregorópulo, Antonio Damilás y otros, véase Aristoteles graecus, pp. $78-83,110-117$ y 209-212. 
y autores de una buena cantidad de mss. repartidos por las bibliotecas europeas. El autor de los ff. ya mencionados del $\Sigma$ III 3 nos parece Jorge Gregorópulo, pero conviene que nos refiramos, aunque sea de pasada, a los problemas que presenta este grupo de copistas. Tenemos, en primer lugar, a Jorge ${ }^{68}$, escriba entre los años 1465 y 1501 que ya hemos mencionado y que fue sacerdote de una iglesia de Candia ${ }^{6 \%}$; Manuel $^{\text {70, }}$ hijo del anterior, estuvo exilado en 1498 en la isla de Car-

68 Véase Vogel-Gardthausen, o. c., pp. $72-73$ (Wittek, "Pour unc étude", p. 292, por errata sin duda, señala $o$. c., pp. 84-85), Patrinelis, o. c., p. 73, Canart, «Scribes grecs», pp. 60 y 74-75, Wiesner-Victor, o. c., p. 54, Harlfinger, Die Textgeschichte, p. 411 y varias menciones en Bernardinello, Autografi, asi como material de interés para su biografia en la conocida obra de E. Legrand, Bibliographie hellénique ou description raisonnée des ouvrages publiés en grec par des grecs au XVe et XVI" siècles, París 1885-1906 (se trata del vol. II, pp. 261-296), M. I. Manússakas, " ‘H

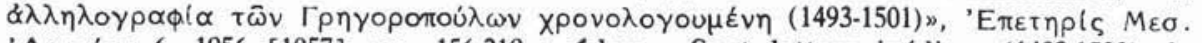
'ApXelou 6, 1956 [1957], pp. 156-219 e 1dem, "Sept lettres inédites (1492-1503) du recueil retrouvé de Jean Gregoropoulos", Thesaurismata 13, 1976, pp. 7-39; útil también es Geanakoplos, o. c., p. 176 ss. y ejemplos de su escritura en Omont. o. c., lám. 21 y Wittek, Album, lám. 38. De él conservamos en El Escorial el $\Sigma$ II 16 (96) que está suscrito en el f. 319v (Revilla lo describe, o. c., pp. 328-330, y edita la suscripción aunque no de forma correcta) y De Andrés, Catálogo, II, pp. 44-45 da como suyo el $\Phi$ II 17 (214), lo que recoge puntualmente C. Casetti Brach, "Copisti greci del Medioevo e del Rinascimento. Aggiunte ai repertori di VogelGardthausen, Patrinelis, Canart, De Meyier e Wiesner-Victor, dai fonti dell'Escorialn, EEBS 42, 1975-1976, p. 240. Nada nuevo añade Harlfinger en sus obras sobre los fondos de nuestro pais que hayan sido copiados por Jorge y bástenos aqui citar - por si hiciera alguna falta subrayarlo- que en el Laurentianus LXXXVII, 11. copiado por él, Miguel Apostolio añadió algo al margen en el f. 175 lo que prueba, una vez más, sus relaciones con el círculo cretense (véase Wiesner, Aristoteles graecus, p. 301).

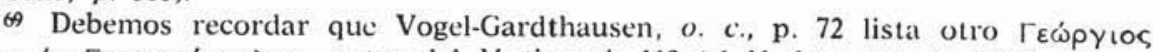

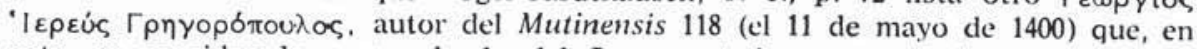
nota, es considerado como abuelo del Jorge anteriormente citado, autor - para

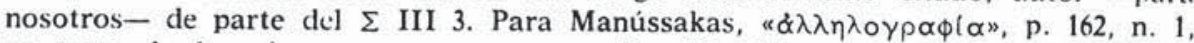
se trata de la misma persona, ya que Vogel-Gardthausen tomaron el dato de V. Puntoni, "Indice dei codici greci della Biblioteca Estense di Modena», SIFC 4. 1896, p. 459, quien leyó 1400 en vez de 1482 que es la fecha exacta del Mutinensis;

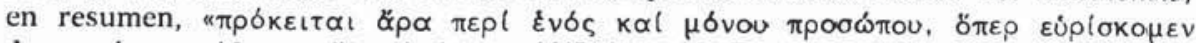

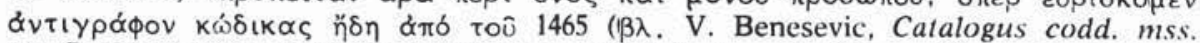

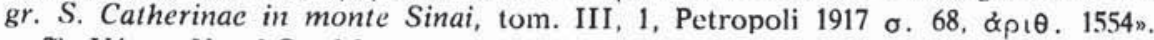

70 Véase Vogel-Gardthausen, $0 . c$., p. 276 y Speck en $B Z 55,1962$, p. 323; Wiesner-Victor, o. c., p. 54 y Harlfinger, Die Textgeschichte, p. 412 así como Aristoteles graecus, p. 156 dan de este copista el $\Sigma$ III 2 (201) que Revilla, o. c., pp. 342 343 describe. Su letra en Omont, o. c., lám. 33 y Harlfinger en Griechische Handschriften und Aldinen, lám. 53. Mss. copias suyas, al igual que hemos visto que ocurría con su padre, los hay realizados junto con Miguel Suliardo y A. Apostolidis, como el Heidelbergensis BU, Palatinus gr. 132 (Aristoteles graecus, pp. 370-372) en el que colaboró también el ya citado Zacharidis (véase n. 41 y bibliografía sobre él en Gamillscheg-Harlfinger, $o$. c., p. 305; una muestra de su letra en Wittek, Album, lám. 47), con A. Apostolidis sólo, como el Leipzig. BU 24 (Aristoteles graecus, pp. 410-411) y con otros más. Los hilos del taller de los Apostolios se cruzan y entrecruzan, pues, y podemos establecer entre sus miembros infinidad de relaciones 
pathos y trabajó igualmente para Miguel Apostolio así como para Aldo Manucio $^{71}$. Finalmente, Juan ${ }^{72}$, el tercero del mismo apellido, fue alum-

simplemente con seguir con nuestra consulta a los catálogos. Volvamos ahora al principio de nuestro estudio, al Escorialensis $\Sigma$ III 3, y al primero de sus copistas conocido, Antonio Damilás; como un ejemplo más que ilustre estas relaciones de las que hablamos, podemos traer a colación el Matritensis BN 4551 (N 13), 11. 1.29 que contiene la Alejandra de Licofrón copiada por Aristóbulo, mientras que en sus ff. 29-31v aparecen los textos que, bajo la autoria de Juan Tzetzes, suclen acompañar a esta pieza (véase nuestro "Una nota sobre el Matritensis BN 4808", Habis 9, 1978, p. 79), copiados éstos por Constantino Láscaris (véase Fernainde\% Pomar, o. c., pp. 217-218, 227, 242 y 284) y a los que siguen (ff. 32-175) otros de la mano de A. Damilás. Como señala Fernández Pomar, las suscripciones de Aristóbulo y Damilás «indican que fueron copiados por encargo de alguien que pagó el importe, pero de ellas no se sigue que éste haya sido Láscaris ni que el importe haya sido pagado in situn; en realidad, los argumentos que esgrime este investigador van dirigidos a probar o negar una posible estancia de Láscaris en Creta en época temprana de su vida y lo que nos interesa aquí es destacar, simplemente, que el papel usado por Aristóbulo lleva la filigrana reproducida por Wittek, "Pour une étude», p. 296, dada como de 1489 (por cierto que el origen de esta conocida filigrana, una mano, es "la mano votiva dedicata al sole, di origine romano-ellenistica" que reproduce A. Basanoff, Itinerario della carta dall'Oriente all'Occidente e sua diffusione in Europa, tr. ital., Milán 1965, lám. VIII). Vogel-Gardthausen, o. c., p. 44, mencionan otra labor de cooperación entre Damilás y Aristóbulo y, aunque siempre quede la duda de que, en ocasiones, se trate de mss. encuadernados juntos y realizados por separado, en otros muchos casos se trata de una realización conjunta. Hay también mss. escritos por Damilás y Miguel Apostolio como el Laurentianus LVIII, 33 copiado entre los años 1462 y 1477 (según conjetura Harlfinger, Aristoteles graecus, p. 211) con el auxilio de una tercera mano, probablemente la de Tomás Bitzimano, copista ya citado, y también el Palatinus 74 (véase P. Siwek, Le "de anima" d'Aristote dans les manuscrits grecs [Studi e Testi, 241]. Ciudad del Vaticano 1965, p. 108); recordemos aquí que Jorge Gregorópulo copió otro de anima, junto con los parua naturalia, en el Parisinus gr. 1861 (véase Siwek, o. c., p. 107 e Idem, Les manuscrits grecs des Parva naturalia d'Aristote [Collectio Philosophica Lateranense, 4], Roma 1961, pp. 71 y 75-78; en este códice hay algunos tratados que también copió Miguel Apostolio en el Vat. Urbinas gr. 39 y Parisinus BN gr. 2035 [Colbertinus 4414, Regius 3082, 3]): el taller cretense se repite en sus encargos y labores y no podía faltar a la cita Zacarías Calliergis quien en el Laurentianus LXXXVII, 22 copió otro de anima en papel con filigrana semejante a Briquet n. 6274 (Treviso 1477) y n." 743 (Venecia 1501) según Harlfinger. Aristoteles graecus, p. 324. Del mismo modo, códices hay también en los que a la letra de Antonio Damilás se añade la de alguno de los Gregorópulos; así, sin ir más lejos, en el tantas veces citado Aristoteles graecus, p. 228, encontramos el Laurentianus LXXI, 5 copiado totalmente por Damilás en Creta en 1480 y del que Manuel Gregorópulo escribió únicamente la mitad inferior del f. 261v, así como el Laurentianus LXXXV, 27 que, junto a las letras de estos dos copistas, presenta también la de César Estratego (Aristoteles graecus, p. 280), copista del que ya hablamos algo en nuestro trabajo mencionado en la n. 17. Bástenos aquí lo dicho sobre las relaciones de estos escribas.

71 Véase sobre él, en general, la conocida obra de A. F. Didot, Alde Manuce et l'hellénisme à Venise, París 1875 (hay reimpresión), todavía valiosa en muchos aspectos, y C. Dionisotti, "Aldo Manuzio Umanista», en Umanesimo Europeo $e$ Umanesimo Veneziano, Florencia 1963, pp. 213-243.

72 Véase Legrand, o. c., p. 266; Patrinelis, o. $c$., p. 74 le atribuye el Mutinensis B. Estensis 101 y en la lám. 56 de Griechische Handschriften und Aldinen (Parisinus 
no de Aristóbulo Apostolidis y amigo y condiscípulo de Marcos Musuro ${ }^{73}$ en Venecia de 1497 a 1500 , muriendo en Italia en 1505; corrector de pruebas con Aldo, fue él quien se ocupó, entre otros, de la edición de Eurípides ${ }^{74}$ y dueño del Parisinus BN suppl. gr. 924 que sirvió de base a la de Filóstrato ${ }^{75}$ (1499); su nombre, además, se relaciona bastante con los ambientes culturales de la época ${ }^{76}$.

De las dificultades para distinguir la letra de Jorge y la de su hijo Manuel ya Canart ${ }^{7}$ dijo en su día: "il m'est actuellement imposible de distinguer avec sécurité les copies de Georges et de son fils Manuel, lorsqu'elles peuvent se situer aux environs de 1490-1505" y la situación no parece haber cambiado mucho a la vista de las observaciones de Harlfinger ${ }^{78}$ y Wiesner ${ }^{79}$. Efectivamente, para este último, en el Florentinus Riccardianus 14 se ve la mano de Jorge mientras que el primero

gr. 1395, f. 15) aparece la letra de Juan de Corone (con marginalia muy probablemente de Marcos Musuro), copista que, según Harlfinger, debe ser identificado con Juan Gregorópulo que escribió también los ff. 3-7v del Guelferbytanus $88 \mathrm{Gud}$. gr. copiado básicamente por Miguel Suliardo (descripción en Griechische Handschriften und Aldinen, pp. 77-79). Comparando esta lámina con los fondos españoles, hemos encontrado, por el momento, que la letra en cuestión es la que copió el Matritensis BN 4549 (N 10) estudiado ya, desde el punto de vista de su texto, por F. Gómez. del Río, "Manuscritos de Jenofonte en Bibliotecas españolas", EMERITA 26, 1958 , pp. 349-354. Sobre Juan de Corone véase Vogel-Gardthausen, o. c., p. 212, Canart, "Scribes grecs", p. 66, Turyn, Byzantine manuscript Tradition, p. 215, B. Schartau, Observations on the activities of the Byzantine Grammarians of the Palaeologian Era, II (Odense University Classical Studies, 3), Odense 1973, p. 46, Harlfinger, Die Textgeschichte, p. 412 y B. Schartau-O. L. Smith, "Towards a descriptive Cataloguc of the Greek Manuscripts of the Royal Library, Copenhagen", Scriptorium 28, 1974, p. 335; otra lámina con su letra en Wittek, Album, lám. 40.

73 Sobre este personaje, como copista (véase n. 72), datos en Vogel-Gardthausen, o. c., pp. 290-291 y Patrinelis, o. c., p. 98; acerca de su faceta de coleccionista de mss. son básicos los trabajos de Mioni, "La biblioteca greca di Marco Musuro", Archivio Veneto, Ser. V, 93, 1971, pp. 5-28 (con muestras de su escritura) y Sicherl, "Musuros-Handschriften" en J. L. Heller-J. K. Newman (eds.), Serta Turyniana. Studies in Greek Literature and Palaeography in Honor of Alexander Turyn, Urbana, Illinois, 1974, pp. 564-608.

74 Véase, en general, «Die editio princeps Aldina des Euripides und ihre Vorlagen", RhM 118, 1975, pp. 205-225.

75 Véase S. Follet, "Contributions à l'histoire de deux manuscrits de Philostrate (Parisini Suppl. gr. 924 et 1256)», RHT, 5, 1975, pp. 1-11.

76 Véase, entre otros, E. Denissoff, Maxime le Grec et l'Occident. Contribution à l'histoire de la pensée religieuse et philosophique de Michel Trivolis, París-Lovaina 1943 , pp. 398-409, A. Oleroff, "L'humaniste dominicain Jean Conon et le crétois Jean Gregoropoulos», Scriptorium 4, 1950, pp. 104-107, Sicherl, "Los comienzos del humanismo griego en Alemania», EstClas 10 (49), 1966, p. 292 y, del mismo autor. Johannes Cuno. Ein Wegbereiter des Griechischen in Deutschland. Eine biographischkodikologische Studie, Heidelberg 1978, passim.

$\pi$ "Scribes grecs", p. 75.

78 Die Textgeschichte, pp. 411 y 412.

79 Aristoteles graecus, p. 355. 
cree reconocer la de Manuel ${ }^{80}$; del mismo modo, hablando del Berolinensis Phill. $1508^{81}$, firmado en Creta por Jorge, Harlfinger señala que "der Duktus - auch in der Subskription- ist jedoch nicht identisch mit dem des Georgios Gregoropulos bei Omont..., sondern mit dem seines Sohnes Manuel (Omont, Taf. 33)». ¿Firmaba el padre los mss. copiados por el hijo o hacía que éste los suscribiera y copiara en su nombre? Es difícil tomar partido; de todas formas, y sin olvidar las debidas cautelas, creemos que en el $\Sigma$ III 3 aparece la mano de Jorge Gregorópulo que con la de A. Damilás y la de A. Apostolidis completan la triada de copistas autores de este códice. Las notas aquí recogidas, para terminar, ponen de relieve una vez más lo mucho que aún queda por hacer en una fase previa de identificación de los copistas de nuestros mss., fase a la que habrán de seguir estudios monográficos sobre cada uno de ellos y sus diversos tipos de letras comparadas con los testimonios manuscritos de las bibliotecas de allende nuestras fronteras $^{82}$

\section{Antonio Bravo Garcia}

80 Por cierto que Jorge es también objeto de discusión a propósito del BM Harleianus 6295 (véase Aristoteles graecus, p. 437) que, para Wiesner, parece ser de este copista mientras que Harlfinger se inclina por Juan Roso aunque, la verdad sea dicha, ambos lo hacen dubitativamente.

81 Aristoteles graecus, p. 43.

\&2 Véase, en general, lo expuesto en nuestras consideraciones finales de la sesión cientifica que llevamos a cabo en el VI Congreso Nacional de Estudios Clásicos (o. c. en n. 67, pp. 221-223). Desde el punto de vista codicológico consúltese el trabajo de De Andrés, "Proyecto para un Corpus Codicum Graecorum Hispanorum". Euphrosyne 7, 1976, pp. 144-151.

P. S. Ya en prensa estas notas, hemos tenido ocasion de consultar la utilísima obra de H. Hunger-E. Gamillscheg-D. Harlfinger, Repertorium der griechischen Kopisten, 800-1600. 1. Handschriften aus Bibliotheken Grossbritaniens (Oesterreichische Akademie der Wiss., Veröffentlichungen der Kommission für Byzantinistik, Band III, 1), Viena 1981, que hace innecesarias algunas de las numerosas indicaciones bibliográficas con que hemos pretendido ayudar al lector español intere. sado en estas cuestiones todavía no demasiado estudiadas en nuestro país. Igualmente, gracias al generoso interés mostrado por nuestros colegas Luis Gil y Antonio Piñero, la penuria bibliográfica del Departamento de Griego de la Universidad Complutense -en lo que a Bizantinística, Paleografía y Codicología griega se refiere - ha comenzado a aliviarse con la adquisición de obras básicas como el Prosopographisches Lexikon der Palaiologenzeit (PLP), entre otras muchas, que hacen también innecesarias parte de las precisiones bibliográficas aquí recogidas, al tiempo que posibilitan un futuro halagüieño para esta clase de investigaciones en España. 